Article

\title{
Extraction of Mangrove Biophysical Parameters Using Airborne LiDAR
}

\section{Wasinee Wannasiri ${ }^{1, *}$, Masahiko Nagai ${ }^{1}$, Kiyoshi Honda ${ }^{2}$, Phisan Santitamnont ${ }^{3}$ and Poonsak Miphokasap ${ }^{4}$}

1 Remote Sensing and GIS, School of Engineering and Technology, Asian Institute of Technology, P.O. Box 4, Klong Luang, Pathumthani 12120, Thailand; E-Mail: nagaim01 @ gmail.com

2 International Digital Earth Applied Science Research Center, Chubu University, 1200, Matsumoto-Cho, Kasugai, Aichi 487-8501, Japan; E-Mail: hondak@isc.chubu.ac.jp

3 Department of Survey Engineering, Chulalongkorn University, 254 Phayathai Road, Pathumwan, Bangkok 10330, Thailand; E-Mail: phisan.chula@gmail.com

4 Department of Geography, Faculty of Social Science, Kasetsart University, 50 Ngam Wong Wan Road, Ladyaow, Chatuchak, Bangkok 10900, Thailand; E-Mail: fsocpsm@ku.ac.th

* Author to whom correspondence should be addressed: E-Mail: wasinee.che@ gmail.com; Tel.: +66-2141-9838; Fax: +66-2143-8405.

Received: 22 February 2013; in revised form: 1 April 2013 / Accepted: 3 April 2013 / Published: 12 April 2013

\begin{abstract}
Tree parameter determinations using airborne Light Detection and Ranging (LiDAR) have been conducted in many forest types, including coniferous, boreal, and deciduous. However, there are only a few scientific articles discussing the application of LiDAR to mangrove biophysical parameter extraction at an individual tree level. The main objective of this study was to investigate the potential of using LiDAR data to estimate the biophysical parameters of mangrove trees at an individual tree scale. The Variable Window Filtering (VWF) and Inverse Watershed Segmentation (IWS) methods were investigated by comparing their performance in individual tree detection and in deriving tree position, crown diameter, and tree height using the LiDAR-derived Canopy Height Model (CHM). The results demonstrated that each method performed well in mangrove forests with a low percentage of crown overlap conditions. The VWF method yielded a slightly higher accuracy for mangrove parameter extractions from LiDAR data compared with the IWS method. This is because the VWF method uses an adaptive circular filtering window size based on an allometric relationship. As a result of the VWF method, the position measurements of individual tree indicated a mean distance error value of $1.10 \mathrm{~m}$. The
\end{abstract}


individual tree detection showed a kappa coefficient of agreement $(K)$ value of 0.78 . The estimation of crown diameter produced a coefficient of determination $\left(R^{2}\right)$ value of 0.75 , a Root Mean Square Error of the Estimate (RMSE) value of $1.65 \mathrm{~m}$, and a Relative Error (RE) value of $19.7 \%$. Tree height determination from LiDAR yielded an $R^{2}$ value of 0.80 , an RMSE value of $1.42 \mathrm{~m}$, and an RE value of $19.2 \%$. However, there are some limitations in the mangrove parameters derived from LiDAR. The results indicated that an increase in the percentage of crown overlap $\left(\mathrm{C}_{\mathrm{OL}}\right)$ results in an accuracy decrease of the mangrove parameters extracted from the LiDAR-derived CHM, particularly for crown measurements. In this study, the accuracy of LiDAR-derived biophysical parameters in mangrove forests using the VWF and IWS methods is lower than in coniferous, boreal, pine, and deciduous forests. An adaptive allometric equation that is specific for the level of tree density and percentage of crown overlap is a solution for improving the predictive accuracy of the VWF method.

Keywords: LiDAR; mangrove; canopy height model; tree height; crown diameter; tree density; crown overlap

\section{Introduction}

Mangroves grow in tropical and subtropical ecosystem regions within intertidal habitats. Mangroves provide various ecological and economical ecosystem services for aquatic habitats, water quality maintenance, medicinal ingredients, coastal erosion reduction, and storm and tsunami protection [1-4]. In addition, mangroves have been highlighted in discussions on global climate change, in particular with reference to Reduced Emissions from Forest Degradation and Deforestation Plus (REDD+). Mangroves have a relatively high greenhouse gas (GHG) removal capacity and a high potential to earn carbon revenues [5-7]. An understanding of mangrove stand biophysical characteristics is necessary for management planning, conservation, and change monitoring. Mangrove parameters, such as tree height and crown diameter, are considered key physical characteristics that are useful for estimating other essential parameters, e.g., the diameter at breast height (DBH), stem volume, and biomass $[8,9]$.

Traditionally, forest biophysical parameters are collected by field observation. Several sampling plots are determined. Then, the individual tree attributes are manually measured. This method is time consuming, labor intensive, and impractical for use in large spatial extents [1,10]. Typically, it is more difficult to access mangrove forests than other forest types. This difficulty mainly results from the soft sediment and muddy land, the heavy prop roots in the swamps, and the daily tidal zone fluctuations [11,12]. Remote sensing techniques, which were reviewed in [1], have demonstrated a high potential to detect, identify, map, and monitor important mangrove parameters. The biophysical characteristics are obtained using several types of sensors, including aerial photography, medium- and high-resolution optical imagery, hyperspectral data, and active microwave observations [13-25]. However, it is difficult to extract the tree stand parameters, such as tree height and canopy profile from these types of data because they do not contain information in the vertical dimension $[1,12,26]$. 
Airborne Light Detection and Ranging (LiDAR) technology makes it possible for scientists to analyze the forest structure in a three-dimensions over large areas [27]. The extraction of biophysical parameters in many forest types, including deciduous [28], conifer [29] and hemiboreal [30], pine [31,32], eucalyptus [33], and urban forests [34] from LiDAR data both at the plot and individual tree level is possible. However, there are only a few scientific articles discussing the application of LiDAR to mangrove biophysical parameter extraction. Most of these studies were focused on the mapping of mangrove distributions [35-38], gap identification [27], and assessment of hurricane disturbance [10]. LiDAR has been used to generate the canopy height profile for validating the mangrove canopy height, which was computed from the Shuttle Radar Topography Mission (SRTM) at the plot level [39,40]. Mangrove forests differ from conifer forests in canopy structure (spherical versus conical crown shape) and from deciduous forests in tree density and canopy closure. These differences may directly affect the LiDAR penetration depth and influence the precision of the derived stand attributes [41]. Thus, scientific research is needed to achieve a better understanding of the LiDAR response over mangrove canopies and to derive accurate parameters at an individual tree scale.

In previous studies, several Individual Tree Crown (ITC) algorithms have been developed to delineate individual tree crowns and measure tree parameters from a LiDAR-derived Canopy Height Model (CHM). Variable Window Filtering (VWF) and Inverse Watershed Segmentation (IWS) are LiDAR processing techniques that are typically applied in a variety of applications. Various studies have applied both algorithms to derive forest attributes [29,32,42,43]. VWF is an adaptive local maximum filtering approach with a circular window of variable window size, which is useful for individual tree crown delineation. IWS initially aims to segment the tree crown over the high-spatial-resolution image [44] and has been recently applied to the LiDAR-derived CHM [43,45]. IWS starts with the inversion of the raster canopy surface into the equivalent of individual hydrologic drainage basins $[29,45]$. The inverted raster is then segmented into distinct crown polygons by automatic processing [29]. However, there are pros and cons of the two methods, which need to be explored in the mangrove forest.

The main objective of this study was to investigate the potential of using LiDAR data for estimating mangrove biophysical parameters at the individual tree level. The VWF and IWS methods were investigated by comparing their performance in individual tree detection and in determining tree position, crown diameter, and tree height. The results of this research will be useful for evaluating the capabilities of LiDAR technology for studying mangrove forests. The possibilities and limitations of mangrove attribute acquisition from LiDAR are also discussed to aid in further algorithm improvements.

\section{Materials and Methods}

\subsection{Study Site}

This research was carried out in Samut-Prakan Province along the coast of the Thai Gulf $\left(102^{\circ} 15^{\prime} \mathrm{E}\right.$, $13^{\circ} 45^{\prime} \mathrm{N}$ ), Thailand (Figure 1(a)). The topographical characteristics of the mangrove habitat are as follows: mudflat terrain and lower than mean sea level between the intertidal zones. The natural mangrove trees in this area vary in age. The dominant mangrove species are Avicennia alba Bl. and Avicennia officinalis L., which are members of the AVICENNIACEAE family. Avicennia are 
generally moderate to large trees and usually have a spherical-shaped canopy. This genus has an aerial root approximately $10-30 \mathrm{~cm}$ in height, which grows from the ground without lobes or prop roots. Due to the height density of the canopy cover, small trees, shrubs and understory plants are not typically found with mangroves [46,47]. To ensure that the collected samples could explain all of the forest structures, three experimental plots (Figure 1(b,c)) with total areas of 1.68 ha were identified with differences in the tree density level and the percentage of crown overlap. Figure 1(d) shows a sample of the mangrove canopy from an IKONOS image.

Figure 1. The location of the study sites in Samut-Prakan Province: (a) mangrove distributions along the coast of Thailand; (b) and (c) locations of the experimental plots; and (d) the mangrove canopy in the study plot from an IKONOS image.

(a)

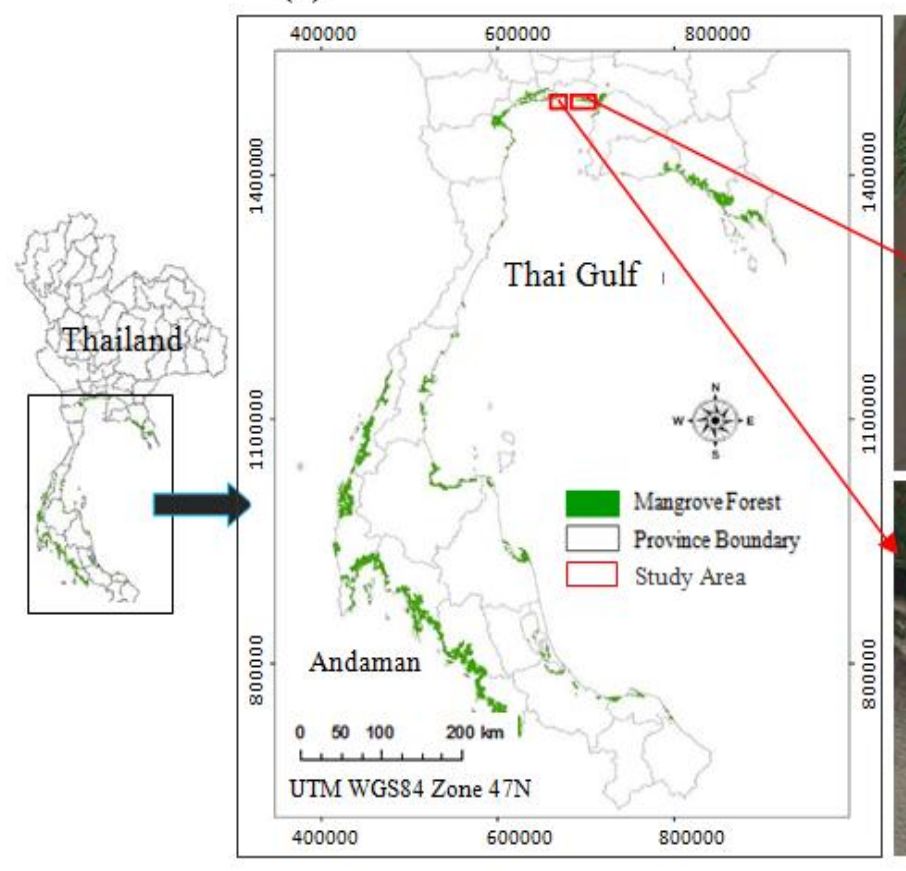

(b)

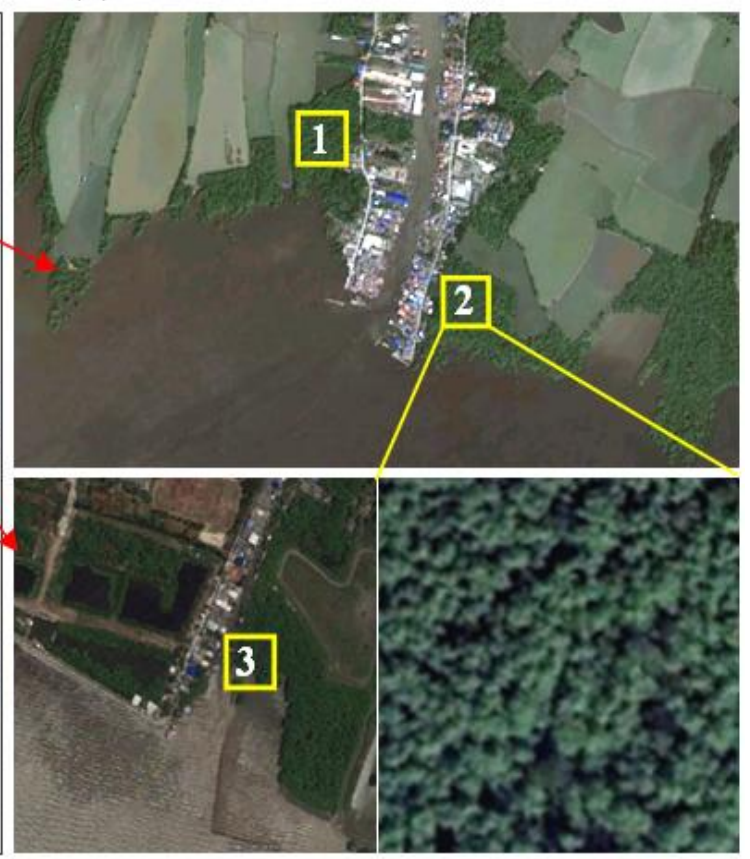

(c) (d)

\subsection{LiDAR Dataset}

The LiDAR data were acquired on June 2005 from 9-12 am at a flight altitude of 1,200 m under clear weather conditions. To avoid the effects of water absorption on the emitted laser pulses, the LiDAR measurement was conducted during low tide. The Royal Thai Survey Department, Chulalongkorn University, and LaserMap GPR Consultants of Canada conducted the LiDAR acquisitions using an Airborne Laser Terrain Mapper 2050 (Optech Inc., Vaughan, ON, Canada) [48], with a specific mission accuracy of approximately $60 \mathrm{~cm}$ and $15 \mathrm{~cm}$ in the horizontal and vertical dimensions, respectively. The scanner transmits the laser pulse and records two returns (first and last). The LiDAR laser points were then classified as vegetation points and ground points using LiDAR software that processed point clouds. The classification of the LiDAR data was performed using TerraScan software, which was developed by Terrasolid Limited of Helsinki, Finland. The details of classification method using TerraScan, which is based on the geometric characteristics of LiDAR point clouds are described in the TerraScan user's guide, 2012 [49,50]. The average laser point density in this study was 
2.7 points per square meter. The LiDAR system technical information is included in Table 1 . Figure 2 shows the vertical mangrove profile of LiDAR data for the front view of the study plot. LiDAR laser points illustrate the height distribution between $-0.3 \mathrm{~m}$ and $13.3 \mathrm{~m}$, which is the range from the mud surface to the top of the canopies.

Figure 2. Vertical mangrove profile of LiDAR data in the study area.

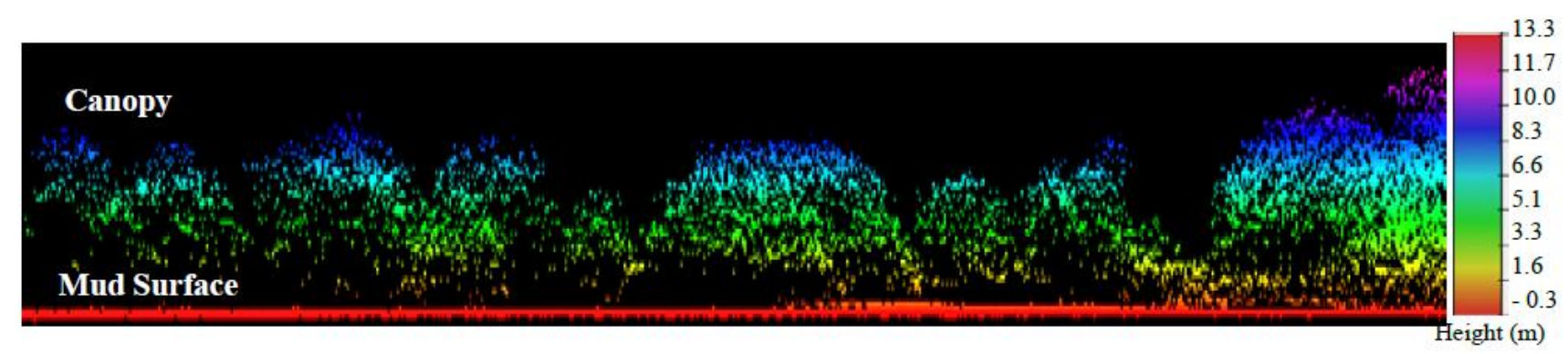

Table 1. The LiDAR dataset specifications.

\begin{tabular}{cc}
\hline Parameter & Specification \\
\hline System & Airborne Laser Terrain Mapper (ALTM) 2050 \\
Horizontal Accuracy & $1 / 2,000 \times$ altitude $(\approx 60 \mathrm{~cm})$ \\
Vertical Accuracy & $15 \mathrm{~cm}$ at $1,200 \mathrm{~m}$ \\
Scanning frequency rate & $28 \mathrm{~Hz}$ \\
Laser repetition rate & $50 \mathrm{kHz}$ \\
Flight altitude & $1,200 \mathrm{~m}$ \\
Swath width & $750 \mathrm{~m}$ \\
Scanning angle & $0^{\circ}$ to $\pm 20^{\circ}$ \\
Footprint & $5 \mathrm{~cm}$ \\
Pulse return & First and last \\
Laser point density & 2.7 points $/ \mathrm{m}^{2}$ \\
\hline
\end{tabular}

\subsection{Field Data Collection}

The measurements of the mangrove characteristics in the three experimental plots were conducted on May 2008. There were five variables collected: actual number of trees, tree position, crown diameter, tree height, and DBH (Table 2). The total area was approximately 0.32 ha, 0.67 ha, and 0.68 ha for plots 1,2 , and 3, respectively. The position at the left corner of each plot was designated as a referent point. Its position in the Universal Transverse Mercator (UTM) geographic coordinate system with WGS84 datum was measured using a GPS receiver. Subsequently, the actual positions of all mangroves $(n=214)$ were manually defined by using a compass and a tape measure to the azimuth angle and the distance from the referent point. The tree height was measured with a laser range finder. Crown diameter, or the average distance between the stem and each cardinal direction, was acquired using a tape measure. The mangroves in the experimental plots vary in age and size. Thus, the collected samples needed to cover the range of tree heights and crown diameters. The descriptive statistics for the collected mangrove samples are summarized in Table 2. 
Table 2. Descriptive statistics for the collected mangrove data.

\begin{tabular}{ccccc}
\hline Descriptive Statistics & Plot 1 & Plot 2 & Plot 3 \\
\hline Plot area (ha) & 0.32 & 0.67 & 0.68 \\
\hline Number of trees & 82 & 80 & 52 \\
\hline Tree density (tree/100 $\left.\mathrm{m}^{2}\right)$ & 2.50 & 1.20 & 0.75 \\
\cline { 2 - 5 } Crown diameter $(\mathrm{m})$ & $\min -\max$ & $3.0-12.0$ & $3.2-14.5$ & $3.5-15.0$ \\
\cline { 2 - 5 } & mean & 7.5 & 8.3 & 9.3 \\
\cline { 2 - 5 } & $\mathrm{SD}$ & 1.2 & 2.9 & 1.8 \\
\cline { 2 - 5 } Tree height $(\mathrm{m})$ & $\min -\max$ & $3.1-11.0$ & $3.3-14.0$ & $3.5-15.5$ \\
\cline { 2 - 5 } & $\mathrm{mean}$ & 7.0 & 7.3 & 7.8 \\
\hline \multirow{3}{*}{ DBH $(\mathrm{cm})$} & $\mathrm{SD}$ & 1.4 & 1.9 & 1.5 \\
\cline { 2 - 5 } & $\min -\max$ & $8.0-31.0$ & $11.0-36.0$ & $8.5-35.1$ \\
\cline { 2 - 5 } & $\mathrm{mean}$ & 17.1 & 20.5 & 23.2 \\
\hline
\end{tabular}

min-max: minimum-maximum; SD: standard deviation

The time lapse between the LiDAR acquisition in 2005 and the field data collection in 2008 had the potential to affect the precision of the mangrove attribute extractions from the LiDAR data. Thus, in 2012, the field survey was re-conducted to monitor the annual growth rate of Avicennia trees, with 30 samples covering the various crown sizes and the height levels. Table 3 summarizes the annual increase in the tree height and crown diameter of alba and officinalis species from 2008 to 2012 within the experimental plots, which were compared with the results of a previous study [51]. The annual increases in height and crown diameter are $13.72 \mathrm{~cm}$ and $14.01 \mathrm{~cm}$, respectively, for Avicennia alba and $14.52 \mathrm{~cm}$ and $15.34 \mathrm{~cm}$, respectively, for Avicennia officinalis. The results indicated that the growth rate of both mangrove species was minimal.

Table 3. Annual increase in Avicennia (A.) alba and officinalis tree height and crown diameter.

\begin{tabular}{|c|c|c|c|c|c|}
\hline \multirow{3}{*}{ Site } & \multicolumn{4}{|c|}{ Annual Increase (cm/year) } & \multirow{3}{*}{ References } \\
\hline & \multicolumn{2}{|c|}{ Tree Height } & \multicolumn{2}{|c|}{ Crown Diameter } & \\
\hline & A. alba & A. officinalis & A. alba & A. officinalis & \\
\hline Samut-Prakan, & 13.72 & 14.51 & 14.02 & 15.34 & \\
\hline Thailand & SD: 2.1 & SD: 2.4 & SD: 5.0 & SD: 4.7 & This study \\
\hline Ranong, Thailand & 13.96 & 16.04 & - & - & [51] \\
\hline
\end{tabular}

For the disturbance and mortality, study site is located in the inner gulf of Thailand which is not an open gulf. Therefore, it is not directly influenced from strong winds or thunderstorms. In addition, mangrove in the study site is a community forest protected by local people. Therefore, the forest is intact and human-caused disturbance is negligible. The data monitoring for the continuous research during 2008-2012 shows that there is no standing dead tree within the study site. The annual growth rates were applied to the sampled data to remove the effects of the time lapse. 


\subsection{Data Analysis}

Several LiDAR processing algorithms have been developed for delineating tree parameters for an individual tree crown. In this study, the VWF and IWS methods were investigated by comparing their tree detection performance and ability in deriving the tree position, crown diameter, and tree height. The overall methodologies are described below.

\subsubsection{Canopy Height Model}

Discrete returns from LiDAR pulses provided three-dimensional information on both the ground and the tree canopy. The Canopy Height Model (CHM) was computed from the canopy laser hits and the corresponding ground laser hits. The LiDAR point clouds were classified as vegetation points and ground points by the vendor using TerraScan software which is based on the geometric characteristics of LiDAR point clouds [49,50]. The vegetation points were then interpolated as a regular grid of the Digital Surface Model (DSM) with a pixel size of $50 \mathrm{~cm}$. The ground points were generated as a Digital Elevation Model (DEM) with the same spatial resolution. The CHM was directly derived by subtracting the DEM from the DSM using the Band Math Tool in ENVI software. In this study, the measured crown diameters of the mangroves ranges from 3 to $15 \mathrm{~m}$, which is equivalent to 6 to 30 pixels on the CHM.

\subsubsection{Crown Overlap}

The percentage of crown overlap $\left(\mathrm{C}_{\mathrm{OL}}\right)$ is one of the key indicators for explaining the level of crown density, which influences to accuracy of forest parameter extractions. Figure 3 presents the process of crown overlap extraction of samples from plot 2. Initially, the CHM was separated into crown and non-crown areas (Figure 3(a)). Subsequently, the actual stem positions were used as a centroid for drawing the circular buffer, based on the radius determined from the field measurements (Figure 3(b)). The crown overlap is the intersection area of the circular buffers (Figure 3(c)). The percentage of crown overlap is the ratio of the total crown area to crown overlap area. Table 4 summarizes the descriptive statistic of the collected mangroves. The percentage of crown overlap and tree density is highest in plot 1 and lowest in plot 3.

Table 4. Descriptive statistics for the collected mangroves.

\begin{tabular}{cccc}
\hline Area $\left(\mathbf{m}^{\mathbf{2}}\right)$ & Plot 1 & Plot 2 & Plot 3 \\
\hline Plot area & 3,248 & 6,750 & 6,885 \\
Crown area & 2,972 & 5,355 & 3,051 \\
Non-Crown area & 276 & 1,395 & 3,834 \\
Crown area overlap & 1,545 & 2,275 & 843 \\
Crown overlap: $\mathrm{C}_{\mathrm{OL}}(\%)$ & 52 & 42 & 28 \\
\hline
\end{tabular}


Figure 3. The process of crown overlap extractions: (a) the CHM was separated into crown and non-crown areas (green boundary); (b) actual stem positions were used as a centroid for generating the circular buffer, based on the field radius (yellow circle); and (c) the crown overlap areas are the intersected regions (yellow pieces).

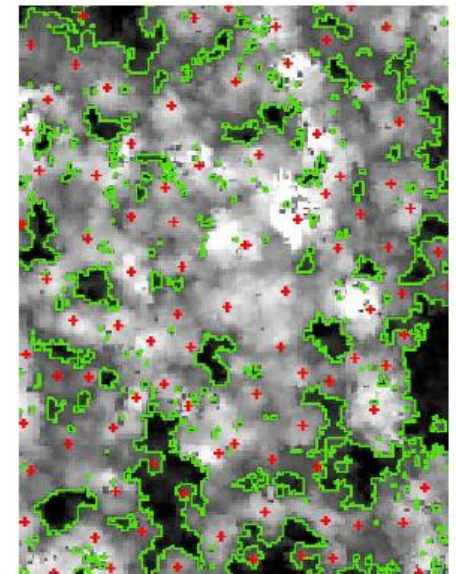

(a)

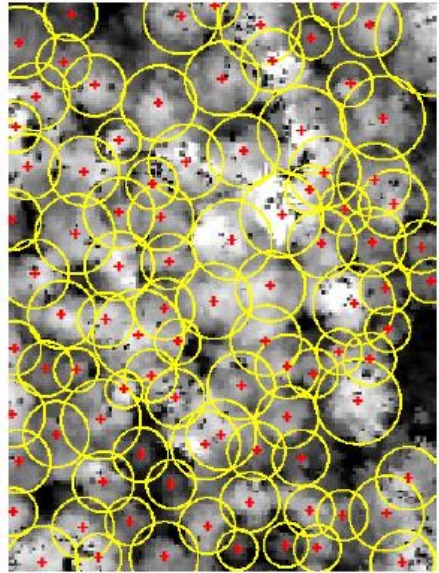

(b)

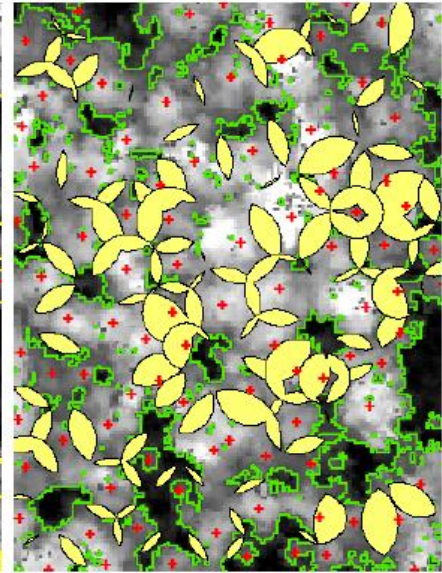

(c)

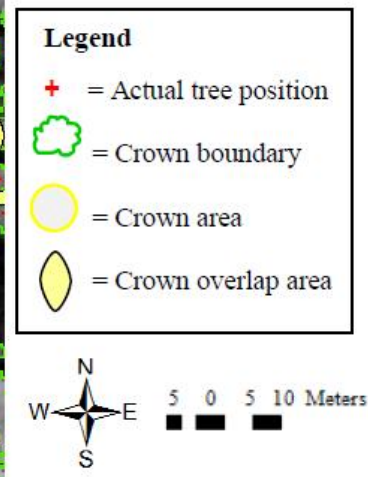

\subsubsection{Variable Window Filtering}

Popescu and Wynne (2004) [42] developed the Tree Variable Window (TreeVaW) program based on single-tree identification using a variable window filtering technique. TreeVaW uses the VWF technique, which involves the extended application of the local maximum focal point in circular window filtering [42,52]. The VWF method aims to identify the treetop and measure the crown size and tree height from the CHM at an individual tree level. The VWF method is a technique used to identify the tree location using a specified and moving window based on the assumption that the highest laser value within a spatial neighborhood represents the tip of the tree crown. The algorithm reads the height value from the $\mathrm{CHM}$ at any pixel and calculates a suitable window size to search for the local maximum. If the considered pixel corresponds to the local maximum, it is flagged as a treetop. Subsequently, the $x-y$ and $z$ values of the corresponding pixel are defined as the tree position and tree height, respectively. The derivation of the appropriate window sizes for searching the treetop relies on the assumption that there is a relationship between tree height and crown size. Thus, two such parameters from the field measurement were used to derive an allometric model that is specific to the Avicennia genus. In this study, an allometric model for Avicennia was developed and is shown in Equation (1). The model was calibrated using the dependent dataset $(n=120)$ and validated by the independent dataset $(n=90)$. The model could explain $71 \%$ of the crown diameter variation with an RMSE value of $1.6 \mathrm{~m}$.

$$
\mathrm{CD}=1.4334 \mathrm{H}-1.7675
$$

where $\mathrm{CD}$ is the crown diameter and $\mathrm{H}$ is the tree height in meters.

In addition, the VWF method requires additional field data, including the minimum tree height for removing the effect of ground pixels and the minimum and maximum crown diameter for specifying an appropriate range of the filtering window size. Then, an individual crown diameter is extracted through the LiDAR-derived CHM by measuring two perpendicular profiles centered on the identified 
treetop. The critical points at both sides of the two extracted perpendicular profiles are determined by fitting a five-degree polynomial function to each profile [52]. The crown diameter is the average distance between the critical points on the two perpendicular profiles.

\subsubsection{Inverse Watershed Segmentation}

Beucher and Lantuéjoul [53] proposed the topographic concept of a watershed for the field of image analysis by segmenting the continuous surface into individual catchment basins. The IWS method involves the extended application of watershed segmentation to individual tree crown delineation by inverting a raster surface to the equivalent of individual hydrologic drainage basins [29,43,54-57]. In this study, the CHM was inverted, which resulted in turning the peaks upside down into depressions. Segmentation could then be performed to delineate tree crowns from a depression model. The ArcHydro extension, which is available in ArcGIS software, was used in this study to segment the individual tree crown from the inverted CHM using image filtering techniques [29]. The individual treetops were located on the CHM by applying zonal filtering based on the maximum height value. The $\mathrm{x}-\mathrm{y}$ and $\mathrm{z}$ values of the corresponding treetop pixel became the tree position and tree height, respectively. The crown diameter was the average of the longest diameter path and its perpendicular line.

\subsubsection{Tree Matching Evaluation}

The accuracy of the determined tree locations was evaluated by comparing the position from the field and the LiDAR measurements. If several extracted tree points had hits on the same tree crown, only the best match according to the distance and height was accepted for inclusion in the analysis. The nearest point to the reference position within the crown boundary or within $3 \mathrm{~m}$ from the crown and the height difference of less than $2 \mathrm{~m}$ was treated as the matching tree [58]. Omission errors involved actual mangroves found in the plots that could not be detected from the LiDAR-derived CHM. The commission error is the number of extra trees extracted from LiDAR that were not found in the plots. The kappa coefficient of agreement $(K)$, which is a consideration of inter-rater agreement, relative observed agreement, and probability of chance agreement, was utilized to evaluate the performance of the VWF and IWS methods for tree extraction. The $K$ value was calculated by the set of equations below:

$$
\begin{gathered}
P r_{\mathrm{a}}=\frac{N_{m}}{N_{S}} \\
C_{e r r}=\frac{N_{c}}{N_{m}+N_{c}+N_{o}} \\
O_{e r r}=\frac{N_{o}}{N_{m}+N_{c}+N_{o}} \\
P r_{e}=C_{e r r}^{2}+O_{e r r}^{2} \\
K=\frac{P r_{a}-P r_{e}}{1-P r_{e}}
\end{gathered}
$$

where $P r_{\mathrm{a}}$ : observed agreement, $P r_{e}$ : chance agreement, $N_{m}$ : number of matching trees (correct), $N_{s}$ : total number of surveyed trees, $N_{c}$ : number of tree points assigned as commission 
errors (false positive), $N_{o}$ : number of tree points assigned as omission errors (false negatives), $C_{e r r}$ : commission error, $O_{e r r}$ : omission error, and $K$ : kappa coefficient of agreement.

\section{Results and Discussion}

\subsection{Individual Tree Detection}

Table 5 summarizes the data for the number of trees and the essential statistics, which were extracted from the LiDAR-derived CHM. The VWF and IWS methods detected 262 and 295 trees, respectively, from 214 actual trees in the pooled dataset. The VWF method detected 186 matched trees (87\%). The IWS method extracted 175 matched trees (82\%). However, both methods still resulted in high commission errors (false positive detection), with a value of 0.26 for the VWF method and a value of 0.36 for the IWS method. The $K$ value, which is the measurement of the correlation between observed and chance agreement, yielded a fairly significant degree of consistency for the individual tree detections, with a value of 0.78 for the VWF method and a value of 0.65 for the IWS method. For the partitioning datasets, the $K$ values vary from 0.56 to 0.87 , which is directly proportional to the crown overlap and tree density. The plot 3 dataset with the lowest percentage of crown overlap (28\%) displayed the highest accuracy for LiDAR tree detection using the VWF method, as indicated by the $K$ value of 0.87 , with a commission error of 0.21 and an omission error of 0.06 .

Table 5. Performances of the VWF and IWS methods in extracting the trees from LiDAR data.

\begin{tabular}{|c|c|c|c|c|c|c|c|c|}
\hline \multirow{3}{*}{$\begin{array}{l}\text { Measure of } \\
\text { Inter-Rater } \\
\text { Agreement }\end{array}$} & \multicolumn{4}{|c|}{ VWF } & \multicolumn{4}{|c|}{ IWS } \\
\hline & \multicolumn{4}{|c|}{$\operatorname{Plot}\left(\mathrm{C}_{\mathrm{OL}} \%\right)$} & \multicolumn{4}{|c|}{$\operatorname{Plot}\left(\mathrm{C}_{\mathrm{OL}} \%\right)$} \\
\hline & $\begin{array}{l}\text { Plot } 1 \\
(52 \%) \\
\end{array}$ & $\begin{array}{l}\text { Plot } 2 \\
(42 \%) \\
\end{array}$ & $\begin{array}{l}\text { Plot } 3 \\
(28 \%) \\
\end{array}$ & $\begin{array}{c}\text { Pooled } \\
\text { Dataset }\end{array}$ & $\begin{array}{l}\text { Plot } 1 \\
(52 \%) \\
\end{array}$ & $\begin{array}{l}\text { Plot } 2 \\
(42 \%) \\
\end{array}$ & $\begin{array}{l}\text { Plot } 3 \\
(28 \%) \\
\end{array}$ & $\begin{array}{c}\text { Pooled } \\
\text { Dataset }\end{array}$ \\
\hline$N_{s}$ & 82 & 80 & 52 & 214 & 82 & 80 & 52 & 214 \\
\hline$N_{i}$ & 102 & 98 & 62 & 262 & 120 & 110 & 65 & 295 \\
\hline$N_{c}$ & 34 & 28 & 14 & 76 & 56 & 46 & 18 & 120 \\
\hline$N_{o}$ & 14 & 10 & 4 & 28 & 18 & 16 & 5 & 39 \\
\hline$N_{m}$ & 68 & 70 & 48 & 186 & 64 & 64 & 47 & 175 \\
\hline$P r_{\mathrm{a}}$ & 0.83 & 0.88 & 0.92 & 0.87 & 0.78 & 0.80 & 0.90 & 0.82 \\
\hline $\operatorname{Pr}_{e}$ & 0.10 & 0.08 & 0.05 & 0.08 & 0.18 & 0.15 & 0.07 & 0.14 \\
\hline$C_{e r r}$ & 0.29 & 0.26 & 0.21 & 0.26 & 0.41 & 0.37 & 0.26 & 0.36 \\
\hline$O_{e r r}$ & 0.12 & 0.09 & 0.06 & 0.10 & 0.13 & 0.13 & 0.07 & 0.12 \\
\hline$K$ & 0.72 & 0.79 & 0.87 & 0.78 & 0.56 & 0.62 & 0.83 & 0.65 \\
\hline
\end{tabular}

$N_{s}$ : total number of surveyed trees, $N_{i}$ : total number of trees derived from LiDAR data, $N_{c}:$ number of tree points assigned as commission errors (false positive), $N_{o}$ : number of tree points assigned as omission errors (false negatives), $N_{m}$ : number of matching trees (correct), $P r_{\mathrm{a}}$ : observed agreement, $P r_{e}$ : chance agreement, $C_{e r r}$ : commission error, $O_{e r r}$ : omission error, $K$ : kappa coefficient of agreement.

As a result, the number of matched trees extracted by the VWF method was slightly superior to that extracted by the IWS method. However, the results indicate overestimation, as illustrated by the high commission errors. There are several factors that may influence tree detection overestimates, including 
CHM pixel size [29], canopy shape, and canopy density [43,58]. For this study, the overestimation is mainly due to the effect of the multiple treetops, which relate to the canopy characteristics and the performance of segmented algorithm. At the study sites, we found that some mangrove trees have several branch peaks associated with the same crown. The IWS method directly delineates the CHM to the segmented tree crowns without the need for a priori field knowledge. Some branches up to the equivalent height of the highest level were segmented into smaller tree crowns. This effect was also found in previous studies by Falkowski et al. [43] and Kaartinen et al. [58]. Their experiments were conducted in conifer forests. However, the VWF method could minimize the effects of multiple treetops by requiring the allometric model to adjust the appropriate circular window sizes for searching the treetop location.

\subsection{Tree Position Accuracy}

The extracted tree positions from the LiDAR data were validated by comparisons with the actual tree positions determined using field measurements. Table 6 illustrates the performance of the VWF and IWS methods in locating the mangrove positions. The pooled dataset yielded RMSE value of $1.10 \mathrm{~m}$ and $1.42 \mathrm{~m}$ using the VWF and IWS method, respectively. Figure 4 shows the spatial distributions of the mangroves as illustrated using green points (VWF), blue rectangles (IWS), and red crosses (actual position). The distance errors of the partitioning datasets range from $0.74 \mathrm{~m}$ to $1.52 \mathrm{~m}$ and $1.05 \mathrm{~m}$ to $1.71 \mathrm{~m}$ using the VWF and IWS method. The results indicate that increases in the distance error are correlated with the percentage of crown overlap and the tree density.

Figure 4. Comparisons of tree positions based on field measurement (red crosses) and positions extracted from the LiDAR-derived CHM using the VWF method (green points) and the IWS method (blue rectangles) for plot 1 (a), plot 2 (b), and plot 3 (c).

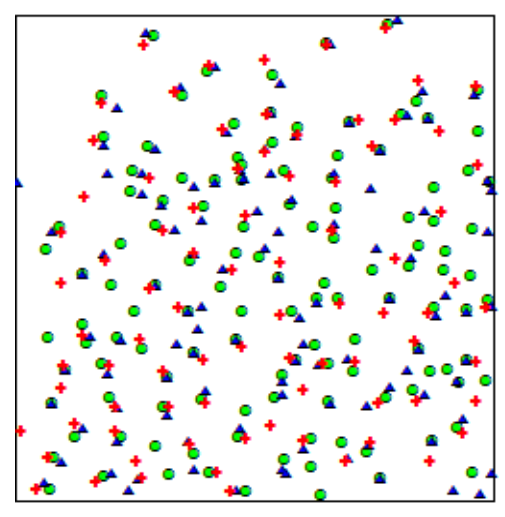

(a)

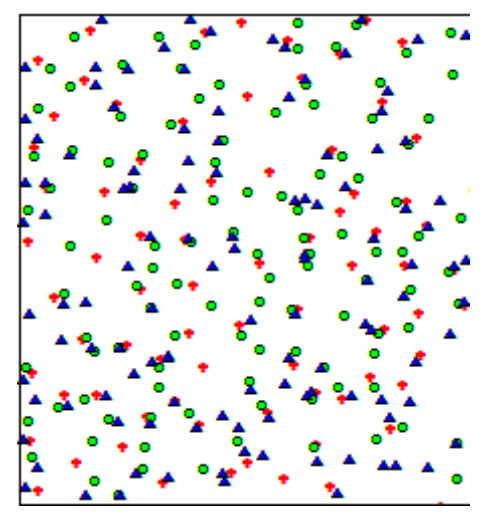

(b)

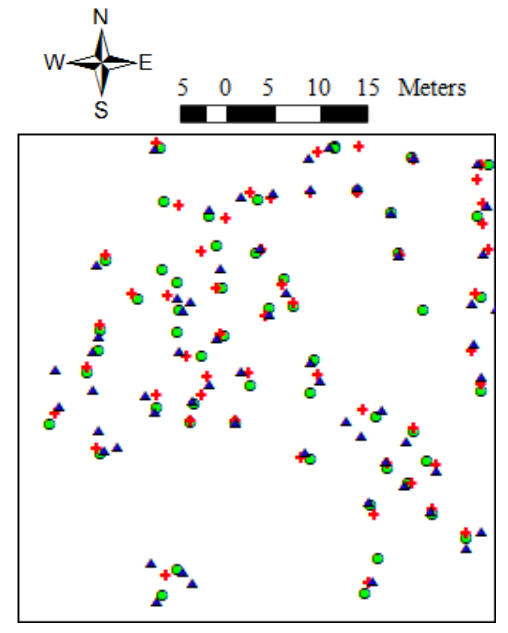

(c)

Table 6 shows that the results derived from the VWF method are better than those based on the IWS method, both for the pooled and partitioning datasets. The UTM geographic coordinate errors at the plot corners influence the predictive accuracy of the tree position extracted from the LiDAR-derived CHM. A handheld GPS unit (Garmin $62 \mathrm{CSX}$ ) was utilized to measure the 
geographical coordinates. The position error is expected to be approximately $2.5-3.0 \mathrm{~m}$ in the horizontal direction. Furthermore, with a geometric specification accuracy of $60 \mathrm{~cm}$ in the horizontal direction, the LiDAR point clouds include some additional distance errors. This issue was also discussed in previous studies [32,59]. In addition, we found that an inclination of mangrove stems is one of the limitations for extracting the mangrove position through LiDAR. A tree position-based LiDAR measurement was defined from the corresponding highest pixel value (treetop) within the segmented crown boundary. However, the tree position based on field measurements was specifically determined at the actual tree base.

Table 6. Performances of the VWF and IWS methods in extracting tree positions from LiDAR data.

\begin{tabular}{cccccc}
\hline \multirow{2}{*}{ Dataset } & \multicolumn{4}{c}{ RMSE $(\mathbf{m})$} \\
\cline { 3 - 6 } & Plot 1 & Plot 2 & Plot 3 & Pooled Dataset \\
\hline \multirow{2}{*}{$\mathrm{C}_{\mathrm{OL}}(\%), \mathrm{D}\left(\right.$ tree $\left./ 100 \mathrm{~m}^{2}\right)$} & $52,2.5$ & $42,1.2$ & $28,0.75$ & - \\
\hline \multirow{2}{*}{ Method } & VWF & 1.52 & 0.97 & 0.74 & 1.10 \\
\cline { 2 - 6 } & IWS & 1.71 & 1.32 & 1.05 & 1.42 \\
\hline
\end{tabular}

$\mathrm{C}_{\mathrm{OL}}$ : Percentage of crown overlap; D: tree density; RMSE: root mean square error

\subsection{Measurement of Crown Diameter}

Table 7 illustrates the performance of two LiDAR processing algorithms in estimating crown diameter. The obtained results from the pooled dataset using the VWF method yielded an $R^{2}$ value of 0.75 , an RMSE value of $1.65 \mathrm{~m}$, and an RE value of $19.7 \%$. The IWS method yielded an $R^{2}$ value of 0.71 , an RMSE value of $1.87 \mathrm{~m}$, and an RE value of $22.4 \%$. The accuracy of crown diameter-based LiDAR measurements for the two proposed methods tends to decrease as the percentage crown overlap and the tree density increases. The plot 1 data, with the highest ratio of $\mathrm{C}_{\mathrm{OL}}(52 \%)$ and tree density $\left(2.5 / 100 \mathrm{~m}^{2}\right)$, yielded the poorest accuracy in crown diameter estimation (IWS: $R^{2}=0.43$, VWF: $R^{2}=0.58$ ). The highest accuracy (IWS: $R^{2}=0.74$, VWF: $R^{2}=0.77$ ) was achieved using the plot 3 dataset, which had the lowest percentage of $\mathrm{C}_{\mathrm{OL}}(28 \%)$ and tree density $\left(0.75 / 100 \mathrm{~m}^{2}\right)$ as illustrated in Table 7.

The results of the VWF method were slightly more accurate than those of the IWS method, with an RMSE difference of $22 \mathrm{~cm}$. This difference is because the VWF method measures the crown features in the CHM while taking into account the crown diameter based on field measurement. The in situ relationships between tree height and crown diameter were explored (Equation (1)) and then utilized to determine the appropriate circular filtering window size for crown diameter estimations. The VWF procedure could reduce the effects of crown fragment and crown overlap, as shown in Figure 5(a-c). In contrast, the crown diameter derived by the IWS method is directly delineated by the CHM without any prior field knowledge. The IWS algorithm cannot capture the crown areas that overlapped with neighboring areas, as shown in Figure $5(\mathrm{~d}-\mathrm{f})$ of plots 1,2 and 3, respectively. Thus, the estimated crown size usually results in many small fragments and leads to underestimation of the crown diameter. Figure 6(a,b) displays the estimated crown diameter derived by using the VWF and IWS methods. The IWS-based results tend to underestimate with a mean difference of $-0.95 \mathrm{~m}$. 
Table 7. Performances of the VWF and IWS methods in estimating crown diameter from LiDAR data.

\begin{tabular}{cccccc}
\hline Dataset & & Plot 1 & Plot 2 & Plot 3 & \multirow{2}{*}{ Pooled Dataset } \\
\hline \multirow{2}{*}{$\mathrm{C}_{\mathrm{OL}}(\%), \mathrm{D}\left(\right.$ tree $\left./ 100 \mathrm{~m}^{2}\right)$} & & $52,2.5$ & $42,1.2$ & $28,0.75$ & \\
\cline { 2 - 5 }$R^{2}$ & VWF & 0.58 & 0.72 & 0.77 & 0.75 \\
\cline { 2 - 5 } & $\mathrm{IWS}$ & 0.43 & 0.63 & 0.74 & 0.71 \\
\hline \multirow{2}{*}{ RMSE $(\mathrm{m})$} & $\mathrm{VWF}$ & 2.14 & 1.71 & 1.53 & 1.65 \\
\cline { 2 - 5 } & $\mathrm{IWS}$ & 2.34 & 2.15 & 1.60 & 1.87 \\
\hline \multirow{2}{*}{$\mathrm{RE}(\%)$} & $\mathrm{VWF}$ & 28.5 & 20.6 & 16.4 & 19.7 \\
\cline { 2 - 5 } & $\mathrm{IWS}$ & 31.2 & 25.9 & 17.2 & 22.4 \\
\hline \multirow{2}{*}{$\mathrm{MD}$} & $\mathrm{VWF}$ & -0.39 & -0.32 & -0.21 & -0.29 \\
\cline { 2 - 5 } & $\mathrm{IWS}$ & -1.03 & -0.97 & -0.93 & -0.95 \\
\hline
\end{tabular}

$\mathrm{C}_{\mathrm{OL}}$ : Percentage of crown overlap; D: tree density; $R^{2}$ : coefficient of determination; RMSE: root mean square error; RE: relative error; MD: mean difference

Figure 5. The extracted mangrove crown (red boundary) based on LiDAR measurements by the VWF (a), (b), (c) and IWS (d), (e), (f) methods of plots 1, 2, and 3, respectively, overlaid on the raster CHM, and compared with the reference locations based on field measurements (blue cross).

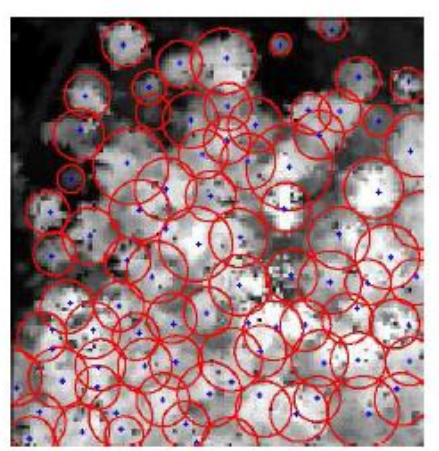

(a)

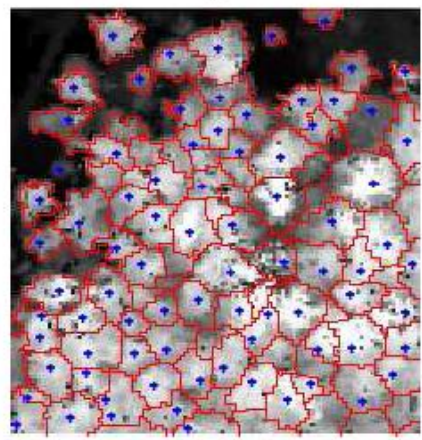

(d)

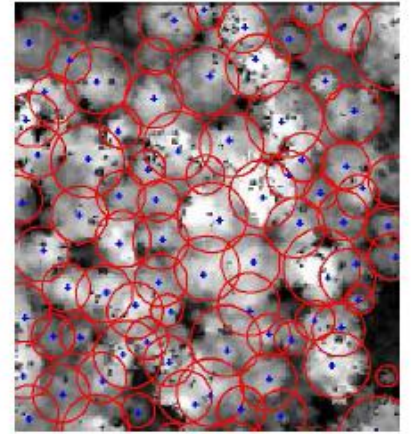

(b)

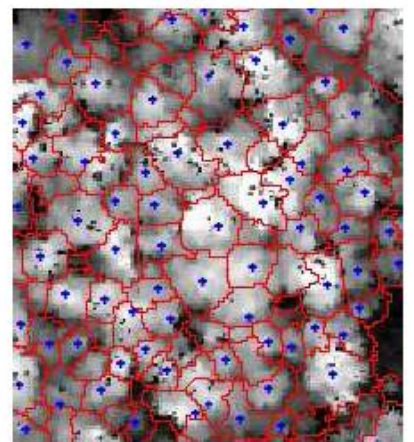

(e)

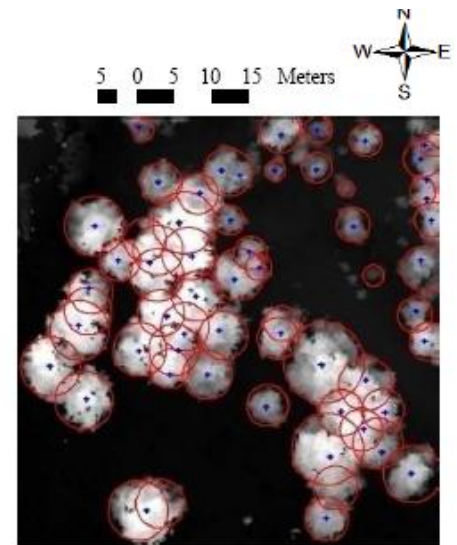

(c)

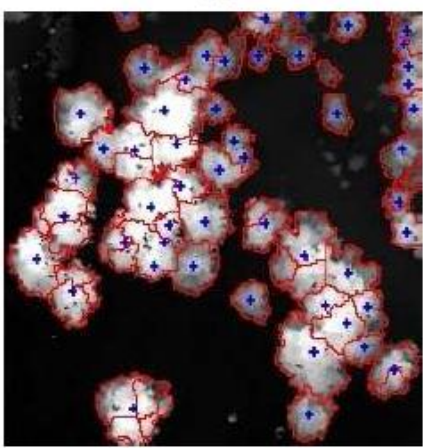

(f)

The accuracy of the LiDAR-extracted crown diameter using the two proposed methods is still quite low, especially in the experimental plots with a dense canopy. There were large relative error values of $28.5 \%$ and $31.2 \%$ in plot 1 for the crown diameter derived by using the VWF and IWS methods, respectively. In the case of the VWF method, this error indicates that the linear relationship 
(Equation (1)) of one independent variable (tree height) might not be sufficient to explain the variations of crown diameter [60,61]. Tree density directly influences the growth rate in the vertical (tree height) and horizontal (crown diameter) directions because it is closely related to the amount of solar radiation penetrating the canopy. Tree height could explain only $71 \%$ of the variance associated with the in situ crown diameter of Avicennia alba and Avicennia officinalis as calculated using Equation (1). Using the IWS method, the tree crown was segmented into several smaller segmented crowns. However, the actual crown size was measured by considering its full extent according to the field inventory. The low accuracy of crown diameter estimation usually occurs in dense mangrove canopies with a high $\mathrm{C}_{\mathrm{OL}}$ percentage. Table 8 shows the estimation capability of the two proposed methods for canopy delineation in different forest types. It should be noted that the performances of the VWF and IWS methods for crown diameter estimation as applied to mangroves are worse than in other forest types, e.g., pine (RMSE $=1.36 \mathrm{~m})$, deciduous $(\mathrm{RMSE}=1.41 \mathrm{~m})$, and mixed conifer forest $(\mathrm{RMSE}=1.66 \mathrm{~m})$.

Figure 6. Field-measured crown diameter versus LiDAR-derived crown diameter using (a) the VWF and (b) IWS methods.

(a)
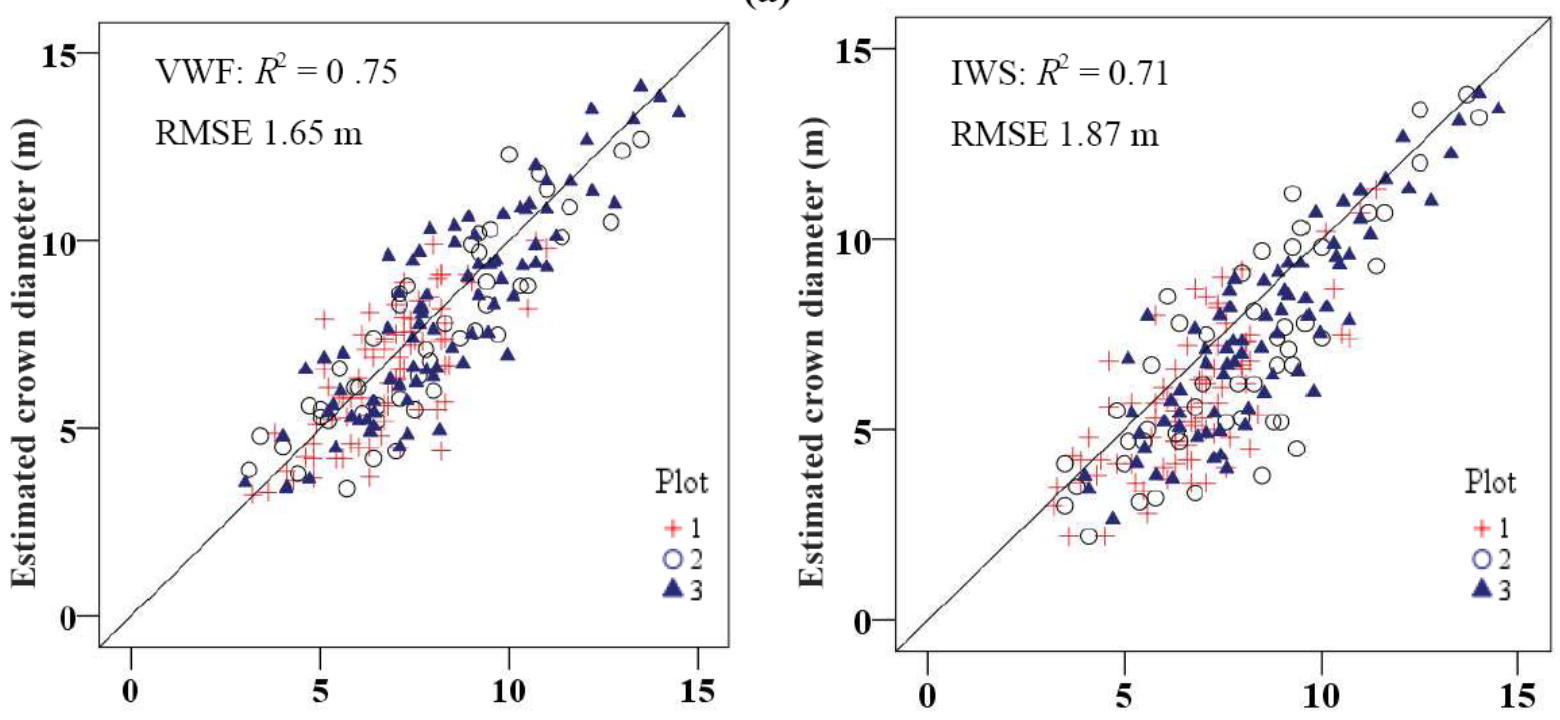

(b)

\subsection{Tree Height Extraction}

Table 8 summarizes the capabilities of the two LiDAR processing algorithms for estimating the tree height from the CHM. The pooled dataset-based VWF method yielded an $R^{2}$ value of 0.80 , an RMSE value of $1.42 \mathrm{~m}$, and an RE value of $19.2 \%$. The IWS method yielded an $R^{2}$ value of 0.77 , an RMSE value of $1.65 \mathrm{~m}$, and an RE value of $22.3 \%$. The results were validated using the reference tree heights $(n=175)$. The scatter plots in Figure $7(\mathrm{a}, \mathrm{b})$ illustrated the comparison of the measured and estimated tree height. It should be noted that the tree height extracted using the VWF and IWS methods tends to underestimate the tree height with MDs of $-0.42 \mathrm{~m}$ and $-0.58 \mathrm{~m}$, respectively. The accuracy of the tree height estimation is closely related to the percentage of crown overlap and tree density. The high percentage of both parameters results in decreasing accuracy for the height estimation, which is similar to results obtained for the crown diameter extraction. 
Table 8. Accuracy of LiDAR-derived biophysical parameters using the VWF and IWS methods in mangrove forests compared with other forest types.

\begin{tabular}{|c|c|c|c|c|c|c|c|}
\hline \multirow[b]{2}{*}{ Forest Type } & \multirow{2}{*}{$\begin{array}{c}\text { Point Cloud } \\
\text { Density } \\
\left(\text { point } / \mathbf{m}^{2}\right)\end{array}$} & \multirow[b]{2}{*}{ Pixel Size } & \multirow[b]{2}{*}{ Method } & \multicolumn{3}{|c|}{$R^{2}$ and (RMSE) } & \multirow[b]{2}{*}{ Reference } \\
\hline & & & & CD (m) & $\mathbf{H}(\mathbf{m})$ & Location $(x, y) m$ & \\
\hline Pine & 1.35 & 0.5 & VWF & $0.62(1.36)$ & $0.97(1.14)$ & - & {$[41,42]$} \\
\hline Deciduous & 1.35 & 0.5 & VWF & $0.63(1.41)$ & $0.79(1.91)$ & - & {$[41,42]$} \\
\hline Mixed Coniferous & $\begin{array}{c}1.95 \mathrm{~m} . \\
\text { (point spacing) }\end{array}$ & 0.5 & VWF & $0.79(1.66)$ & $0.97(2.81)$ & - & [43] \\
\hline Coniferous & 8 & 0.5 & VWF & - & $(0.28)$ & $(2.19)$ & [31] \\
\hline Coniferous & 8 & 0.5 & IWS & - & $(0.22)$ & $(2.31)$ & [31] \\
\hline Boreal & - & 1.0 & IWS & (1.46) & (1.23) & - & [54] \\
\hline Mangrove & 2.7 & 0.5 & VWF & $0.75(1.65)$ & $0.80(1.42)$ & $(1.10,1.25)$ & This study \\
\hline Mangrove & 2.7 & 0.5 & IWS & $0.71(1.87)$ & $0.77(1.65)$ & $(1.53,1.74)$ & This study \\
\hline
\end{tabular}

CD: crown diameter; H: height; $R^{2}$ : coefficient of determination; RMSE: root mean square error.

Figure 7. Tree height measured versus LiDAR-derived tree height (a) and (b) using the VWF and IWS methods, respectively.

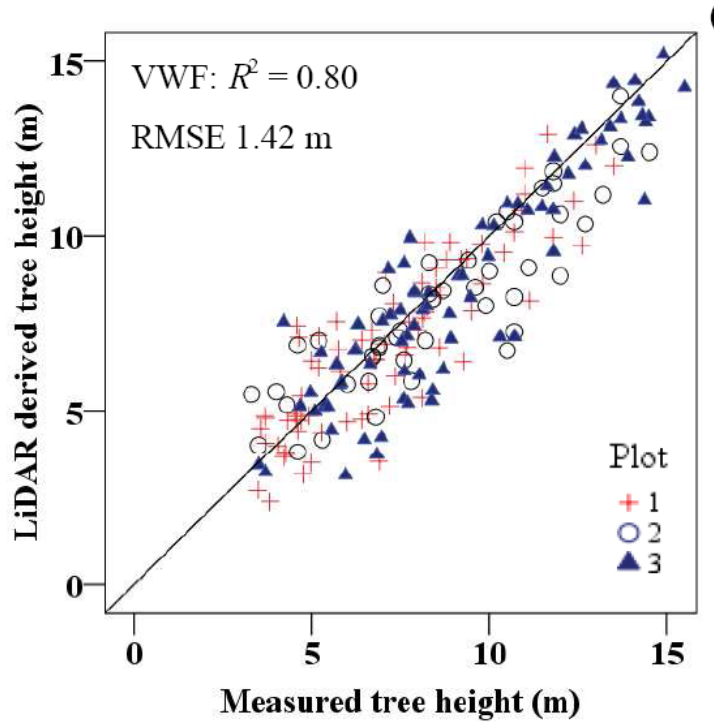

(a)

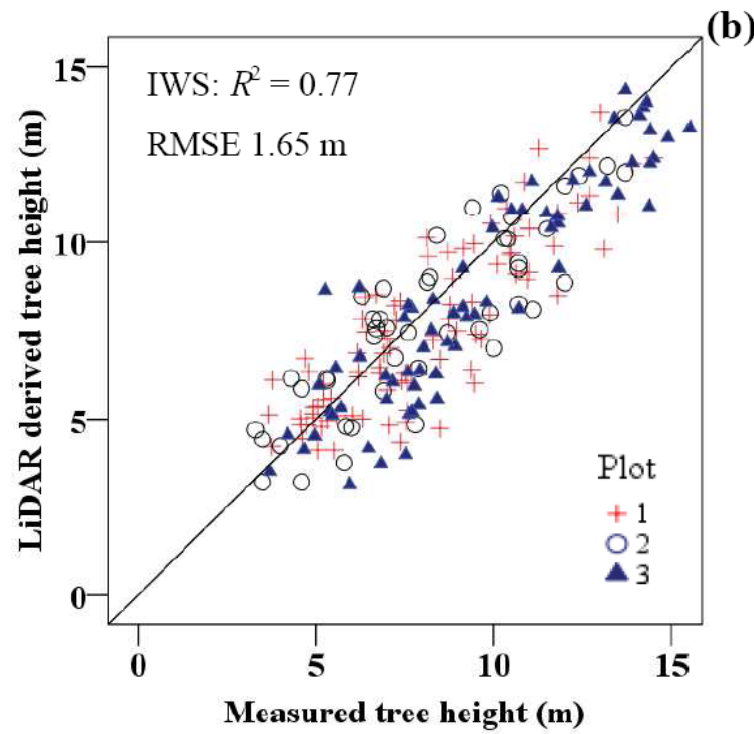

The VWF method produced more accurate results for tree height determination than the IWS method, with differences in an RMSE of $23 \mathrm{~cm}$ and an RE of 3.1\% (Table 9). The limitations of tree height extraction from LiDAR measurements of mangroves can be summarized by highlighting several issues, which is consistent with previous studies [34-37,62-65]. The tree height error measurements usually occur in areas of high canopy density [66,67] because of the low probability of an emitted laser pulse striking the top of a tree crown rather than elsewhere on the crown [31,43]. The low probability of an emitted laser pulse reaching the ground in a dense forest affects the accuracy of DEM, particularly for valleys or mountains [68]. Nevertheless, the mangroves in this study were typically 
located in mudflat terrain where this effect could be avoided. In addition, the inclination of the stem can be a problem for tree height measurement of mangroves based on LiDAR data. Inclined trees are usually a result of wave force and the instability of mudflat terrain. The pixel value corresponding to the treetop in the LiDAR data was defined as the tree height. For the field measurements, the tree height was the length from the tree base to the treetop along the inclined stem. This effect leads to the underestimation of tree height. Table 8 summarizes the accuracy of LiDAR-derived mangrove biophysical parameters using the VWF and IWS methods compared with previous studies in different forest types. The accuracy of the height estimation using LiDAR data for mangrove forests is lower than the accuracy for coniferous [31,43] spruce, pine [41,42,44], and boreal [54] forests. However, the results of this study cannot be compared directly with previous studies because of the differences in the LiDAR point cloud density, tree species, forest structure, and crown density.

Table 9. Performance of the VWF and IWS methods for estimating tree height.

\begin{tabular}{|c|c|c|c|c|c|}
\hline \multicolumn{2}{|c|}{ Dataset } & Plot 1 & Plot 2 & Plot 3 & Pooled \\
\hline \multicolumn{2}{|c|}{$\mathrm{C}_{\mathrm{OL}}(\%), \mathrm{D}\left(\right.$ tree $\left./ 100 \mathrm{~m}^{2}\right)$} & $52,2.5$ & $42,1.2$ & $28,0.75$ & Dataset \\
\hline \multirow{2}{*}{$R^{2}$} & VWF & 0.76 & 0.77 & 0.82 & 0.80 \\
\hline & IWS & 0.72 & 0.73 & 0.78 & 0.77 \\
\hline \multirow{2}{*}{ RMSE (m) } & VWF & 1.68 & 1.55 & 1.45 & 1.42 \\
\hline & IWS & 1.74 & 1.58 & 1.53 & 1.65 \\
\hline \multirow{2}{*}{$\operatorname{RE}(\%)$} & VWF & 24.0 & 21.2 & 18.6 & 19.2 \\
\hline & IWS & 24.9 & 21.6 & 19.6 & 22.3 \\
\hline \multirow{2}{*}{ MD } & VWF & -0.25 & -0.52 & -0.55 & -0.42 \\
\hline & IWS & -0.41 & -0.53 & -0.78 & -0.58 \\
\hline
\end{tabular}

$\mathrm{C}_{\mathrm{OL}}$ : Percentage of crown overlap; D: tree density; $R^{2}$ : coefficient of determination; RMSE: root mean square error; RE: relative error; MD: mean difference.

\section{Conclusions}

This study aims to estimate the biophysical parameters of tropical mangrove from an airborne Light Detection and Ranging (LiDAR)-derived Canopy Height Model (CHM). An experiment was conducted at the individual tree level. Two LiDAR processing techniques, Variable Window Filtering (VWF) and Inverse Watershed Segmentation (IWS), were investigated by comparing their performance in individual tree detection and in deriving tree position, crown diameter, and tree height. The most important possibilities and limitations of LiDAR for mangrove attribute acquisition that can be drawn from the results of this study are as follows:

(i) The VWF method yielded a slightly higher accuracy for mangrove parameter extractions from LiDAR-derived CHM compared with the IWS method. The accuracy of the VWF method depends on the allometric relationships between tree height and crown diameter. In contrast, the IWS method does not require an empirical and site-specific allometric model. The benefits of IWS are that it is convenient and it saves time. However, the automatic segmentation of the tree crown usually results in small fragments, particularly in dense mangrove canopies. This problem 
affects the high commission error of the individual tree detection and underestimation of the crown diameter.

(ii) The VWF and IWS methods can detect individual mangroves from the LiDAR-derived CHM with an accuracy of $87 \%$ and $82 \%$ and mean position error values of $1.10 \mathrm{~m}$ and $1.42 \mathrm{~m}$, respectively. Both methods have high commission errors, which results in an overestimate of trees. This overestimation is mainly due to the effect of the multiple treetops, which relate to the canopy characteristics and segmented algorithms. However, the VWF method shows the kappa coefficient of agreement $(K)$ value of 0.78 . The VWF method could minimize this effect by requiring the allometric model to specify the appropriate circular window filtering size for searching the treetop location.

(iii) An increase in the percentage of crown overlap $\left(\mathrm{C}_{\mathrm{OL}}\right)$ results in an accuracy decrease of the mangrove parameters extracted from the LiDAR-derived CHM. In addition, $\mathrm{C}_{\mathrm{OL}}$ strongly affected the accuracy of crown diameter extractions, especially when the IWS method was utilized. The results of the IWS method tended to underestimate the crown diameter, with a Mean Difference (MD) value of $-0.95 \mathrm{~m}$.

(iv) For the tree height estimation from the LiDAR-derived CHM, the VWF method yielded the highest coefficient of determination $\left(R^{2}\right)$ value of 0.80 and Root Mean Square Error (RMSE) value of $1.42 \mathrm{~m}$. The VWF method was superior to the IWS method, with an RMSE difference value of $23 \mathrm{~cm}$. The results tended to underestimate the tree height, with MD values of -0.42 to $-0.58 \mathrm{~m}$.

(v) In this study, the accuracy of the LiDAR-derived biophysical parameters in mangrove forests using the VWF and IWS methods is lower than in coniferous, boreal, pine, and deciduous forests. The lower estimation accuracy is mainly due to differences in forest density, canopy structure and density of the LiDAR point clouds.

The results presented herein suggest that future developments of the VWF method are required to improve individual tree detection and crown diameter estimation in mangrove forests. An adaptive allometric equation that is specific for the level of tree density and percentage of crown overlap is a solution for increasing the predictive accuracy of the VWF method. In addition, linear regression based on an independent variable (height) might not be sufficient for explaining the variations of crown diameter. Thus, the integration of other variables, e.g., $\mathrm{DBH}$, age, and $\mathrm{C}_{\mathrm{OL}}$, to the allometric model could possibly improve the accuracy. Moreover, a nonlinear relationship, e.g., logarithmic or polynomial, should be considered.

\section{Acknowledgments}

This research was funded by the Biodiversity Research and Training Program (BRT), National Centre for Genetic Engineering and Biotechnology (BIOTEC), Ministry of Science and Technology, Thailand. The author would like to acknowledge Department of Survey Engineering at Chulalongkorn University for providing the LiDAR data. We thank the anonymous reviewers whose comments substantially improved this paper. 


\section{References}

1. Kuenzer, C.; Bluemel, A.; Gebhardt, S.; Quoc, T.V.; Dech, S. Remote sensing of mangrove ecosystems: A Review. Remote Sens. 2011, 3, 878-928.

2. Food and Agricultural Organization (FAO). Management and Utilization of Mangroves in Asia and Pacific; FAO Environment Paper No.3; Agriculture Department: Rome, Italy, 1982; p. 166.

3. Harada, K.; Imamura, F. Experimental Study on the Effect in Reducing Tsunami by the Coastal Permeable Structures. In Proceedings of the Twelfth International Offshore and Polar Engineering Conference, Kitakyushu, Japan, 26-31 May 2002; pp. 652-658.

4. Danielsen, F.; Sørensen, M.K.; Olwig, M.F.; Selvam, V.; Parish, F.; Burgess N.D.; Hiraishi, T.; Karunagaran, V.M.; Rasmussen, M.S.; Hansen, L.B.; et al. The Asian Tsunami: A protective role for coastal vegetation. Science 2005, doi: 10.1126/science.1118387.

5. Lieth, H., Whittaker, R.H., Eds. Primary Production of the Major Vegetation Units of the World. In Primary Productivity of the Biosphere; Springer: Berlin/Heidelberg, Germany, 1975; pp. 305-328.

6. McNally, R.; McEwin, A.; Holland, T. The Potential for Mangrove Carbon Projects in Vietnam; SNV-Netherlands Development Organisation REDD+ Programme: Ha Noi, Vietnam, 2011.

7. Kristensen, E.; Bouillon, S.; Dittmar T.; Marchand, C. Organic carbon dynamics in mangrove ecosystems: A review. Aquat. Bot. 2008, 89, 201-219.

8. Komiyama, A.; Poungparn, S.; Kato, S. Common allometric equations for estimating the tree weight of mangroves. J. Trop. Ecol. 2005, 21, 471-477

9. Komiyama. A.; Ong. J.E.; Poungparn, S. Allometry, biomass, and productivity of mangrove forests: A review. Aquat. Bot. 2007, 89, 128-137.

10. Zhang, K.; Simard, M.; Ross, M.; Rivera-Monroy, V.H.; Houle, P.; Ruiz, P.; Twilley, R.R.; Whelan, K. Airborne laser scanning quantification of disturbances from hurricanes and lightning strikes to mangrove forests in Everglades National Park, USA. Sensors 2008, 8, 2262-2292.

11. Cole, T.G.; Ekel, K.C.; Devoe, N.N. Structure of mangrove tree and forest in Micronesia. Forest Ecol. Manage. 1999, 117, 95-109.

12. Malthus, T.J.; Mumby, P.J. Remote sensing of the coastal zone: An overview and priorities for future research. Int. J. Remote Sens. 2003, 24, 2805-2815.

13. Lucas, R.M.; Ellison, J.C.; Mitchell, A.; Donnelly, B.; Finlayson, M.; Milne, A.K. Use of stereo aerial photography for quantifying changes in the extent and height of mangroves in tropical Australia. Wetlands Ecol. Manage. 2002, 10, 161-175.

14. Giri, C.; Pengra, B.; Zhu, Z.; Singh, A.; Tieszen, L.L. Monitoring Mangrove forest dynamics of the Sundarbans in Bangladesh and India using multi-temporal satellite data from 1973 to 2000. Estuar. Coast. Shelf Sci. 2007, 73, 91-100.

15. Wang, L.; Sousa, W.P.; Gong, P.; Biging, G.S. Comparison of IKONOS and QuickBird imagery for mapping mangrove species on the Caribbean coast of Panama. Remote Sens. Environ. 2004, 91, 432-440.

16. Yang, C.; Everitt, J.H.; Fletcher, R.S.; Jensen, R.R.; Mausel, P.W. Evaluating AISA+ hyperspectral imagery for mapping black mangrove along the South Texas Gulf Coast. Photogramm. Eng. Remote Sensing 2009, 75, 425-435. 
17. Wang, L.; Sousa, W.P. Distinguishing mangrove species with laboratory measurements of hyperspectral leaf reflectance. Int. J. Remote Sens. 2009, 30, 1267-1281.

18. Meza Diaz, B.; Blackburn, G.A. Remote sensing of mangrove biophysical properties: Evidence from a laboratory simulation of the possible effects of background variation on spectral vegetation indices. Int. J. Remote Sens. 2003, 24, 53-73.

19. Alongi, D.M. Mangrove forests: Resilience; protection from tsunamis; and responses to global climate change. Estuar. Coast. Shelf Sci. 2008, 76, 1-13.

20. Cochard, R.; Ranamukhaarachchi, S.L.; Shivakoti, G.P.; Shipin, O.V.; Edwards, P.J.; Seeland, K.T. The 2004 tsunami in Aceh and Southern Thailand: A review on coastal ecosystems; wave hazards and vulnerability. Perspect. Plant Ecol. Evol. Syst. 2008, 10, 3-40.

21. Lucas, R.M.; Mitchell, A.L.; Rosenqvist, A.; Proisy, C.; Melius, A.; Ticehurst, C. The potential of L-band SAR for quantifying mangrove characteristics and change: Case studies from the tropics. Aquat. Conserv. 2007, 17, 245-264.

22. Kovacs, J.M.; Vandenberg, C.V.; Wang, J.; Flores-Verdugo, F. The use of multipolarized spaceborne SAR backscatter for monitoring the health of a degraded mangrove forest. J. Coast. Res. 2008, 24, 248-254.

23. Souza Filho, P.W.; Paradella, W.R. Use of RADARSAT-1 fine mode and Landsat-5 TM selective principal component analysis for geomorphological mapping in a macrotidal mangrove coast in the Amazon Region. Can. J. Remote Sens. 2005, 31, 214-224.

24. Ozdemir, I. Estimating stem volume by tree crown area and tree shadow area extracted from pan-sharpened Quickbird imagery in open Crimean juniper forests. Int. J. Remote Sens. 2008, 29, 5643-5655.

25. Myint, S.W.; Giri, C.P.; Wang, L.; Zhu, Z.; Gillette, S. Identifying mangrove species and their surrounding land use and land cover classes using an object oriented approach with a lacunarity spatial measure. GIScience Remote Sens. 2008, 45, 188-208.

26. Lovell, J.L.; Jupp, D.L.B.; Newnham, G.J.; Coops, N.C.; Culvenor, D.S. Simulation study for finding optimal lidar acquisition parameters for forest height retrieval. Forest Ecol. Manage. 2005, 214, 398-412.

27. Zhang. K. Identification of gaps in mangrove forests with airborne LiDAR. Remote Sens. Environ. 2007, 112, 2309-2325.

28. Brandtberg, T.; Warner, T.A.; Landenberger, R.E.; McGraw, J.B. Detection and analysis of individual leaf-off tree crowns in small footprint, high sampling density lidar data from the eastern deciduous forest in North America. Remote Sens. Environ. 2003, 85, 290-303.

29. Edson, C.; Wing, M.G. Airborne Light Detection and Ranging (LiDAR) for individual tree stem location, height, and biomass measurements. Remote Sens. 2011, 3, 2494-2528.

30. Lindberg, E.; Hollaus, M. Comparison of methods for Estimation of stem volume, stem number and basal area from Airborne laser scanning data in a hemi-boreal forest. Remote Sens. 2012, 4, 1004-1023.

31. Pirotti, F. Assessing a template matching approach for tree height and position extraction from lidar-derived canopy height models of pinus pinaster stands. Forests 2010, 1, 194-208.

32. Popescu, S.C. Estimating biomass of individual pine and trees using airborne lidar. Biomass Bioenergy. 2007, 31, 646-655. 
33. Tesfamichael, S.G.; van Aardt, J.A.N.; Ahmed, F. Estimating plot-level tree height and volume of Eucalyptus grandis plantations using small-footprint, discrete return lidar data. Progr. Phys. Geogr. 2010, 34, 515-540.

34. Shrestha, R.; Wynne, R.H. Estimating biophysical parameters of individual trees in an urban environment using small footprint discrete-return imaging lidar. Remote Sens. 2012, 4, 484-508.

35. Long, G.C.; Larry, J.T. Mapping and monitoring Louisiana's Mangroves in the aftermath of the 2010 gulf of Mexico oil spill. J. Coastal Res. 2011, 27, 1059-1064,

36. Benjamin W.H. Satellite remote sensing of mangrove forests: Recent advances and future opportunities. Progr. Phys. Geogr. 2011, 35, 87-108.

37. John, C. Integrated LiDAR and IKONOS multispectral imagery for mapping mangrove distribution and physical properties. Int. J. Remote Sens. 2011, 32, 6765-6781.

38. Zhang, K.; Patricia, A.H.; Michael, S.R.; Pablo, L.R.; Marc, S. Airborne Laser Mapping of Mangroves on the Biscayne Bay Coast, Miami, Florida. In Proceedings of IEEE International Conference on Geoscience and Remote Sensing Symposium, 2006 (IGARSS 2006), Miami, FL, USA, 31 July-4 August 2006; pp. 3750-3754.

39. Temilola F.E.; Marc, S. Height and biomass of mangroves in Africa from ICESat/GLAS and SRTM. Int. J. Remote Sens. 2013, 34, 668-681.

40. Simard, M.; Rivera-Monroy, V.H.; Mancera-Pineda, J.E.; Castañeda-Moya, E.; Twilley, R.R. A systematic method for 3D mapping of mangrove forests based on Shuttle Radar Topography Mission elevation data, ICEsat/GLAS waveforms and field data. Remote Sens. Environ. 2008, 112, 2131-2144.

41. Falkowski, M.J.; Smith, A.M.S.; Gessler, P.E.; Hudak, A.T.; Vierling, L.A.; Evans, J.S. The influence of conifer forest canopy cover on the accuracy of two individual tree measurement algorithms using lidar data. Can. J. Remote Sens. 2008, 34, S338-S350.

42. Popescu, S.C.; Wynne, R.H. Seeing the trees in the forest: Using lidar and multispectral data fusion with local filtering and variable window size for estimating tree height. Photogramm. Eng. Remote Sensing 2004, 70, 589-604.

43. Falkowski, M.J.; Smith, A.M.S.; Hudak, A.T.; Gessler, P.E.; Vierling, L.A.; Crookston, N.L. Automated estimation of individual conifer tree height and crown diameter via two dimensional spatial wavelet analysis of lidar data. Can. J. Remote Sens. 2006, 32, 153-161.

44. Jing, L.; Hu, B.; Noland, T.; Li, J. An individual tree crown delineation method based on multi-scale segmentation of imagery. ISPRS J. Photogramm. 2012, 70, 88-98.

45. Chen, Q.; Baldicchi, D.; Gong, P.; Kelly, M. Isolation individual tree in a savanna woodland using small footprint LiDAR Data. Photogramm. Eng. Remote Sensing 2006, 72, 923-932.

46. Mangrove Resource Convention Office, Department of Marine and Coastal Resources. Mangrove in Thailand; The Communities of Agriculture and Cooperatives: Bangkok, Thailand, 2009; p.167.

47. Kitamura, S.; Anwar, C.; Chaniago, A.; Baba, S. Handbook of Mangroves in Indonesia; The International Society for Mangrove Ecosystem: Saritaksu Denpasar, Bali, Indonesia, 1997; p.199.

48. Optech Incorporated. ALTM 2050 Airborne Laser Terrain Mapper: The Ultimate in Performance. Optech Incorporated: Toronto, ON, Canada, 2002.

49. Soininen, A. TerraScan User's Guide; The National Mapping Agency of Great Britain: Southampton, UK, 2012. 
50. Hugelschaffer, D. Use of LiDAR in Forestry Applications; Sunpine Forest Products Ltd: Sundre, AB, Canada, 2004.

51. Kaewwong, A.; Boonyawat, S.; Aksornkoae, S.; Tabthipwon, P. The Suitable Mangrove Tree Species for Planting on the Abandoned Mining Area, Changwat Ranong. In Proceedings of 39th Kasetsart University Annual Conference: Science, Natural Resources and Environmental Economics, Bangkok, Thailand, 4-5 February 2001; Volume 1, pp. 409-417.

52. Popescu, S.C.; Wynne, R.H.; Nelson, R.F. Measuring individual tree crown diameter with lidar and assessing its influence on estimating forest volume and biomass. Can. J. Remote Sens. 2003, 29, 564-577.

53. Beucher, S.; Lantuéjoul, C. Use of Watersheds in Contour Detection. In Proceedings of International Workshop on Image Processing, Real-Time Edge and Motion Detection, Rennes, France, 17-21 September 1979.

54. Andersen, H.E. Using airborne light detection and ranging (lidar) to characterize forest stand condition on the Kenai Peninsula of Alaska. West. J. Appl. Forest. 2009, 24, 95-102.

55. Ziegler, M.; Konrad, M.; Hofrichter, J.; Wimmer, A.; Ruppert, G.; Schardt, M.; Hyyppa, J. Assessment of forest attributes and single-tree segmentation by means of forest scanning. Proc. SPIE 2000, 4035, 73-84.

56. Hyppä, J.; Kelle, O.; Lehikoinen, M.; Inkinen, M. A segmentation-based method to retrieve stem volume estimates from 3-D tree height models produced by laser scanners. IEEE Trans. Geosci. Remote Sens. 2001, 39, 969-975.

57. Schardt, M.; Ziegler, M.; Wimmer, A.; Wack, R.; Hyyppä, J. Assessment of forest parameters by means of laser scanning. Int. Arch. Photogramm. Remote Sens. 2002, 34, 302-309.

58. Kaartinen H.; Hyyppä, J.; Yu X.; Vastaranta M.; Hyyppä, H.; Kukko, A.; Holopainen, M.; Heipke, C.; Hirschmugl M.; Morsdorf F.; et al. An international comparison of individual tree detection and extraction using airborne laser scanning. Remote Sens. 2012, 4, 950-974.

59. Persson, Å.; Holmgren, J.; Södermann, U. Detecting and measuring individual trees using an airborne laser scanner. Photogramm. Eng. Remote Sensing 2002, 68, 925-932.

60. Arzai, A.H.; Aliyu, B.S. The relationship between canopy width, height and trunk size in some tree species growth in the Savana zone of Nigeria. Bayero J. Pure Appl. Sci. 2010, 3, 260-263.

61. Mugo, J.M.; Njunge, J.T.; Malimbwi, R.E.; Kigomo, B.N.; Mwasi B.N.; Muchiri, M.N. Models for predicting stem diameter from crown diameter of open grown trees in Sondu-Nyando river catchment, Kenya. Asian J. Agric. Sci. 2011, 3, 119-126.

62. Eysn, L.; Hollaus, M.; Schadauer, K.; Pfeifer, N. Forest delineation based on airborne lidar data. Remote Sens. 2012, 4, 762-783.

63. Hyyppä, J.; Inkinen, M. Detecting and estimating attributes for single trees using laser scanner. Photogramm. J. Finl. 1999, 16, 27-42.

64. Hopkinson, C.; Chasmer, L.; Sass, G.; Creed, I.; Sitar, M.; Kalbfleisch, W.; Treitz, P. Vegetation class dependent errors in lidar ground elevation and canopy height estimates in a boreal wetland environment. Can. J. Remote Sens. 2005, 31, 191-206.

65. Maltamo, M.; Mustonen, K.; Hyyppä, J.; Yu, X. The accuracy of estimating individual tree variables with airborne laser scanning in a boreal nature reserve. Can. J. Forest Res. 2004, 34, 1791-1801. 
66. Gaveau, D.L.A.; Hill, R. Quantifying canopy height underestimation by laser pulse penetration in small-footprint airborne laser scanning data. Can. J. Remote Sens. 2003, 29, 650-657.

67. Chasmer, L.; Hopkinson, C.; Treitz, P. Investigating laser pulse penetration through a conifer canopy by integrating airborne and terrestrial lidar. Can. J. Remote Sens. 2006, 32, 116-125.

68. Hyyppä, J.; Pyysalo, U.; Hyyppä, H.; Samberg, A. Elevation of Accuracy of Laser Scanning-Derived Digital Terrain and Target Models in Forest Environment. In Proceedings of EARSeL-SIG-Workshop LIDAR, Dresden, Germany, 16-17 June 2000.

(C) 2013 by the authors; licensee MDPI, Basel, Switzerland. This article is an open access article distributed under the terms and conditions of the Creative Commons Attribution license (http://creativecommons.org/licenses/by/3.0/) 